\title{
Plasma microRNA-451 as a novel hemolytic marker for $\boldsymbol{\beta}^{0}$-thalassemia/HbE disease
}

\author{
KAMONLAK LEECHAROENKIAT ${ }^{1}$, YUKA TANAKA ${ }^{2}$, YASUKO HARADA ${ }^{2}$, \\ PORNTIP CHAICHOMPOO $^{3}$, ORAWAN SARAKUL ${ }^{4}$, YASUNOBU ABE ${ }^{5}$, DUNCAN RICHARD SMITH ${ }^{6}$, \\ SUTHAT FUCHAROEN $^{7}$, SAOVAROS SVASTI $^{7,8}$ and TSUKURU UMEMURA ${ }^{2,9}$
}

\begin{abstract}
${ }^{1}$ Department of Clinical Microscopy, Faculty of Allied Health Sciences, Chulalongkorn University, Bangkok 10330, Thailand;
${ }^{2}$ Division of Medical Technology, Department of Health Sciences, Faculty of Medical Sciences, Kyushu University,

Fukuoka 812-8582, Japan; ${ }^{3}$ Department of Pathobiology, Faculty of Science, Mahidol University, Bangkok 10400;

${ }^{4}$ Department of Medical Technology, School of Allied Health Sciences, Walailak University,

Nakhon Si Thammarat 80160, Thailand; ${ }^{5}$ Department of Medicine, Graduate School of Medical Sciences, Kyushu University, Fukuoka 812-8582, Japan; ${ }^{6}$ Molecular Pathology Laboratory; ${ }^{7}$ Thalassemia Research Center,

Institute of Molecular Biosciences, Mahidol University, Salaya, Nakhon Pathom 73170;

${ }^{8}$ Department of Biochemistry, Faculty of Science, Mahidol University, Bangkok 10400, Thailand;

${ }^{9}$ Department of Medical Technology and Sciences, International University of Health and Welfare, Ohkawa, Fukuoka 831-8501, Japan
\end{abstract}

Received December 16, 2015; Accepted February 6, 2016

DOI: $10.3892 / \mathrm{mmr} .2017 .6326$

\begin{abstract}
In Southeast Asia, particularly in Thailand, $\beta^{0}$-thalassemia/hemoglobin E (HbE) disease is a common hereditary hematological disease. It is associated with pathophysiological processes, such as the intramedullary destruction of immature erythroid cells and peripheral hemolysis of mature red blood cells. MicroRNA (miR) sequences, which are short non-coding RNA that regulate gene expression in a suppressive manner, serve a crucial role in human erythropoiesis. In the present study, the plasma levels of the erythroid-expressed miRNAs, miR-451 and miR-155, were analyzed in 23 patients with $\beta^{0}$-thalassemia/HbE and 16 control subjects. Reverse transcription-quantitative polymerase chain reaction analysis revealed significantly higher levels of plasma miR-451 and miR-155 in $\beta^{0}$-thalassemia/HbE patients when compared to the control subjects. Notably, among the $\beta^{0}$-thalassemia/HbE
\end{abstract}

Correspondence to: Professor Tsukuru Umemura, Department of Medical Technology and Sciences, International University of Health and Welfare, 137-1 Enokizu, Ohkawa, Fukuoka 831-8501, Japan

E-mail: umemura@iuhw.ac.jp

Dr Saovaros Svasti, Thalassaemia Research Center, Institute of Molecular Biosciences, Mahidol University, Salaya Campus, 25/25 Phuttamonthon 4 Road, Salaya, Phuttamonthon, Nakhon Pathom 73170, Thailand

E-mail: saovaros.sva@mahidol.ac.th

Key words: microRNA, plasma, microRNA-451, thalassemia, hemolysis patients, a significant increase in miR-451 levels was detected in severe cases when compared with mild cases. The levels of plasma miR-451 correlated with reticulocyte and platelet counts. The results suggest that increased plasma miR-451 levels may be associated with the degree of hemolysis and accelerated erythropoiesis in $\beta^{0}$-thalassemia/HbE patients. In conclusion, miR-451 may represent a relevant biomarker for pathological erythropoiesis associated with $\beta^{0}$-thalassemia/HbE.

\section{Introduction}

$\beta$-thalassemia consists of a diverse group of inherited blood disorders, which are characterized by abnormalities in $\beta$-globin production (1). In Southeast Asia, particularly in Thailand, the most common and severe type of compound heterozygous $\beta$-thalassemia is $\beta^{0}$-thalassemia/hemoglobin $\mathrm{E}(\mathrm{HbE})$ disease (2). The $\beta^{0}$-thalassaemia/HbE phenotype is caused by co-inheritance of a $\beta$-thalassemia allele from one parent and a structural $\mathrm{HbE}$ variant from the other parent. $\mathrm{HbE}$ is induced following the substitution of a lysine for glutamic acid at codon 26 of $\beta$-globin. As a result, b-globin is unstable in vitro and is rapidly degraded, which leads to a functional deficiency $(3,4)$.

$\beta^{0}$-thalassaemia/HbE is primarily associated with a reduction in $\beta$ chain synthesis, which leads to a globin chain imbalance, ineffective erythropoiesis, oxidative damage and shortened red blood cell survival $(1,5)$. HbE instability is a minor factor in the overall pathophysiology of $\beta^{0}$-thalassaemia/HbE. However, during intercurrent complications, such as infection or febrile illnesses, it may result in accelerated red cell hemolysis $(3,6)$. In $\beta^{0}$-thalassemias, two major pathways are involved in erythroid cell destruction; the first induces premature destruction of erythroid precursors in the bone marrow and is known as 
ineffective erythropoiesis $(5,7)$, while the second induces hemolysis through the destruction of mature red blood cells (RBCs) containing unmatched $\alpha$-globin inclusions in the blood circulation (7). The loss of erythroid precursors and/or mature RBCs leads to anemic conditions, thus promoting increased production of erythropoietin (EPO) from the kidneys. The increased level of EPO subsequently promotes increased erythroid expansion and extramedullary erythropoiesis (8).

$\beta^{0}$-thalassemia/HbE is classified as a disease associated with extravascular hemolysis, as abnormal RBCs are engulfed by the reticuloendothelial system, thus inducing splenomegaly and hypersplenism $(5,9)$. A splenectomy is performed to reduce the risk of spleen-induced extravascular hemolysis in patients exhibiting signs of hypersplenism, which increases blood transfusion requirements (9). A previous study reported increased levels of serum cell-free $\mathrm{Hb}$, which provides evidence of intravascular hemolysis (10).

MicroRNAs (miRNAs/miR) are a class of short singlestranded RNAs, 20 to 25 nucleotides in length in the mature form, which negatively regulate target genes at the post-transcriptional level by degrading complementary mRNA or inhibiting its translation $(11,12)$. miRNAs are important molecules involved in development, and cell proliferation, differentiation and apoptosis (13). Previous studies have demonstrated that miRNAs are highly abundant and stable in the blood circulation $(14,15)$. Examinations of circulating miRNA profiles in the plasma or serum obtained from normal healthy subjects have suggested that a number of circulating miRNAs may be of blood cell origin (16). Circulating miRNAs are considered to be a useful non-invasive biomarker for various diseases $(17,18)$.

A previous study investigated the expression patterns of 4 miRNAs (miR-451, miR-155, miR-223 and miR-221) during normal eythropoiesis using reverse transcription-quantitative polymerase chain reaction (RT-qPCR) analysis (19). This previous study focused on miR-451, an erythroid cell-specific miRNA $(20,21)$, which was revealed to be upregulated during erythroid maturation (19). It has been demonstrated that miR-451 promotes the maturation of committed erythroblasts, and the hematopoietic transcription factor, GATA-binding factor 1, directly regulates its expression (22). Functional studies using gain-and loss-of-function approaches have demonstrated that miR-451 is associated with human erythroid maturation (23). By contrast, cellular expression of miR-155 in cultured erythroid cells markedly decreased during maturation, and was 200-fold lower in mature RBCs $(19,24)$.

miR-155 has been previously characterized as a multifunctional miRNA that serves an important role in pathological processes associated with a number of diseases, including cancer, inflammation, immunity and cardiovascular diseases (25). In addition, overexpression of miR-155 as an oncogenic miRNA in hematological malignancies and solid tumors has been reported $(26,27)$.

In the present study, the authors hypothesized that the levels of erythroid specific miRNAs would increase in the plasma of patients with intravascular hemolysis, particularly in severe cases. miR-451 and miRNA-155 levels were analyzed in plasma samples from patients with $\beta^{0}$-thalassemia/ $\mathrm{HbE}$ and normal control subjects, using a rapid and sensitive quantitative RT-qPCR assay.

\section{Materials and methods}

Subjects. The present study was conducted with the approval of the Ethics Committee from the Mahidol University Institutional Review Board (Mahidol University, Nakhon Pathom, Thailand) and informed consent was obtained from each participant (age 18-50 years) enrolled at the Nakhon Pathom Hospital (Nakhon Pathom, Thailand) between April 2010 and May 2011. A total of 6 ml EDTA-preserved blood from 23 patients with $\beta^{0}$-thalassemia/HbE (10 mild and 13 severe cases) and 16 (normal control subjects) were collected. There were 12 females and 11 males for the $\beta^{0}$-thalassemia/ $\mathrm{HbE}$ cohort and 10 females and 6 males for normal control subjects. The normal control subjects were screened to be free of thalassemia using red blood cell (RBC) indices, hemoglobin typing, multiplex gap-PCR and reverse dot blot hybridization. Standard methods, including complete blood count (CBC), $\mathrm{Hb}$ typing and reverse dot blot hybridization were used for diagnosis of $\beta^{0}$-thalassemia/HbE (28). CBCs and RBC indices of the control subjects and $\beta^{0}$-thalassemia/HbE patients were determined using an automated cell counter (ADVIA 210; Bayer, Pittsburgh, PA, USA). Hb typing was performed using an automatic high performance liquid chromatography system following manufacturer's instructions (VARIANT II $^{\mathrm{TM}}$ Hemoglobin Testing systems; Bio-Rad Laboratories, Inc., Hercules, CA, USA). The double-heterozygous state for $\beta^{0}$-thalassemia and $\mathrm{HbE}$ alleles in all patients was confirmed by reverse dot blot hybridization according to the previously described protocol (28). Briefly, the $\beta$-globin gene was amplified using four biotinylated primers named China 1, China 2, China 3, China 4, (Bio-Synthesis, Lewisville, TX, USA). The sequences of the modified primers are as follows: China 1, 5'-biotin GTACGGCTGTCATCACTTAGACCTCA-3'; China 2, 5'-biotinTGCAGCTTGTCACAGTGCAGCTCA CT-3'; China 3, 5'-biotin GTGTACACATATTGACCAAA-3'; China 4, 5'-biotinAGCACACAGACCAGCACGTT-3' (28). Amplified DNA products were hybridized with immobilizing allele-specific oligonucleotide probes on a nylon membrane (Biodyne C; Pall Life Sciences, Port Washington, NY, USA) at $45^{\circ} \mathrm{C}$ for $30 \mathrm{~min}$. Detection of the hybridization reaction was performed by conjugation of streptavidin-alkaline phosphatase (Roche Applied Science, Penzberg, Germany). The severity grading of $\beta^{0}$-thalassemia/ $\mathrm{HbE}$ patients was performed based on six parameters including: Hemoglobin level, age at disease presentation, age at receiving first blood transfusion, requirement for transfusion, spleen size, and growth and development, following the standard protocol as described previously (29).

Plasma RNA preparation. A total of $6 \mathrm{ml}$ EDTA-preserved blood samples were centrifuged at $650 \times \mathrm{g}$ for $20 \mathrm{~min}$ at room temperature. Plasma was separated from the samples and was filtered through a $0.45 \mu \mathrm{M}$ Minisart ${ }^{\circledR}$ syringe filter membrane (Merck Millipore, Darmstadt, Germany). A total of $200 \mu \mathrm{l}$ plasma was diluted with $50 \mu \mathrm{l}$ RNase free water and $1 \mu \mathrm{l}$ glycogen (Applied Biosystems; Thermo Fisher Scientific, Inc., Waltham, MA, USA) prior to homogenization with $750 \mu 1$ Isogen-LS reagent (Nippon Gene Co., Ltd., Tokyo, Japan) by vortexing and pipetting. Synthetic cel-miR-39 RNA (1 fmol; Qiagen GmbH, Hilden, Germany) was spiked into the denatured sample solution. Chloroform $(200 \mu \mathrm{l})$ was subsequently 
added, and the suspension was shaken vigorously. The samples were then centrifuged at $18,000 \mathrm{~g}, 4^{\circ} \mathrm{C}$ for $15 \mathrm{~min}$, and the RNA in the aqueous phase was precipitated by adding $400 \mu \mathrm{l}$ isopropanol for $10 \mathrm{~min}$ at room temperature. RNA pellets were washed with $1 \mathrm{ml}$ ethanol (70\%) and resolubilized in $15 \mu \mathrm{l}$ RNase-free water.

RNA preparation from packed red cells. The packed red cells were separated from the same cohort, including 9 normal subjects, 9 mild and 9 severe $\beta^{0}$-thalassemia/HbE patients Following separating plasma from whole blood samples by centrifugation at $650 \times \mathrm{g}$ for $20 \mathrm{~min}$ at room temperature, the remaining fraction was further used to separate packed red cells by density gradient centrifugation using Lymphoprep

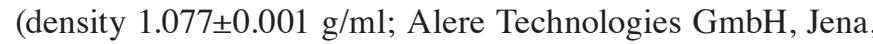
Germany) to eliminate mononuclear cells. A total of $100 \mu \mathrm{l}$ of packed red cells were separated and homogenized with $750 \mu \mathrm{l}$ Isogen-LS reagent (Nippon Gene Co., Ltd.). A total of $200 \mu \mathrm{l}$ chloroform was added, and the suspension was shaken vigorously. The homogenized samples were centrifuged at $18,000 \mathrm{~g}$ for $15 \mathrm{~min}$ before RNA in the aqueous phase was separated into a fresh tube and precipitated by incubating in $400 \mu \mathrm{l}$ isopropanol for $10 \mathrm{~min}$ at room temperature. RNA pellets were washed with $1 \mathrm{ml}$ ethanol (70\%) and resolubilized in $15 \mu \mathrm{l}$ RNase-free water.

RT-qPCR analysis. A fixed volume of $5 \mu 1$ eluted RNA solution was reverse transcribed to cDNA using looped specific primers for cel-miR-39, human miR-451, human miR-155 and let-7a obtained from TaqMan MicroRNA assay kits (Applied Biosystems; Thermo Fisher Scientific, Inc., Waltham, MA, USA; cat. nos. 478293_mir, 478107_mir, 477927_mir, 478575_mir, respectively), and a $\operatorname{TaqMan}^{\circledR}$ MicroRNA Reverse Transcription kit (Applied Biosystems; Thermo Fisher Scientific, Inc.) according to the manufacturer's instructions. For detection of the miRNAs, qPCR analysis was performed using TaqMan MicroRNA assay kits and Universal PCR Master Mix (Applied Biosystems; Thermo Fisher Scientific, Inc.; cat. no. 4304437). PCR was performed using the Takara Thermal Cycler Dice (Takara Bio, Inc., Otsu, Japan). Each reaction was performed in duplicate. For RT-qPCR analysis of plasma miR-451 and miR-155 expression, the expression of a known quantity of spiked cel-miR-39 was used for normalization (Applied Biosystems; Thermo Fisher Scientific, Inc.). The quantification cycle $\left(\mathrm{C}_{\mathrm{q}}\right)$ of miR-451 and miR-155 was used to calculate the $\Delta \mathrm{C}_{\mathrm{q}}$ value using the following formula: $\Delta \mathrm{C}_{\mathrm{q}}=\mathrm{C}_{\mathrm{q} \text { (cel-miR-39) }}-\mathrm{C}_{\mathrm{q} \text { (miRNA of interest) }}$. Therefore, a higher $\Delta \mathrm{C}_{\mathrm{q}}$ value indicated a higher expression level of the miRNA of interest. For the analysis of cellular miR-451 in packed red cells, the expression of let-7a was used for normalization. The $\Delta \mathrm{C}_{\mathrm{q}}$ value of miR-451 was calculated from the $\mathrm{C}_{\mathrm{q}}$ of the miRNAs by subtracting miR-451 from the average $\mathrm{C}_{\mathrm{q}}$ of let-7a.

Statistical analysis. The association between plasma miR-451, miR-155 levels and disease severity was analyzed by compared the levels of each miRNA between the mild and severe group using the Student's $t$-test. Mann-Whitney $U$ tests were used to evaluate differences between two groups. Receiver operating characteristic (ROC) curves were plotted to evaluate the diagnostic accuracy of each miRNA. The sensitivity and specificity of the cut-off values were defined as the maximized area under the ROC curve (AUC) with a 95\% confidence interval value. The correlation between miR-451 or miR-155 and clinical laboratory parameters was evaluated using the Pearson's correlation test. $\mathrm{P}<0.05$ was considered to indicate a statistically significant difference. Statistical analyses were performed using the GraphPad Prism software (version, 5.0; GraphPad Software, Inc., La Jolla, CA, USA).

\section{Results}

Clinical data of patients with $\beta^{\circ}$-thalassemia/HbE. The clinical data of the 16 control subjects and 23 patients with $\beta^{0}$-thalassemia/HbE are shown in Table I. A total of 11 male and 12 female patients with $\beta^{0}$-thalassemia/HbE, and 5 male and 11 female control subjects were employed in the current study. Out of the 23 patients with $\beta^{0}$-thalassemia/HbE, a total of 10 were splenectomized. Patients with $\beta^{0}$-thalassemia/ $\mathrm{HbE}$ exhibited significantly lower RBC counts, $\mathrm{Hb}$ level, hematocrit (Hct), mean corpuscular volumes (MCV), mean corpuscular $\mathrm{Hb}$ (MCH) and mean corpuscular Hb concentrations (MCHC) (all $\mathrm{P}<0.05)$, however, they exhibited significantly higher reticulocyte counts $(\mathrm{P}<0.05)$, when compared with the normal control subjects (Table I). Furthermore, severe $\beta^{0}$-thalassemia/HbE patients exhibited significantly higher reticulocyte and platelet counts, and significantly lower RBC counts, Hb, MCV and MCHC levels (all $\mathrm{P}<0.05$ ) when compared with mild $\beta^{0}$-thalassemia/HbE patients (Table I).

Increased levels of plasma miR-451 and miR-155 in patients with $\beta^{0}$-thalassemia/HbE. The present study used the synthetic miRNA, cel-miR-39 as an internal control. Cel-miR-39 was recovered from normal controls and $\beta^{0}$-thalassemia/HbE plasma samples at the same level as indicated by the average $\mathrm{C}_{\mathrm{q}}$ values of $27.97 \pm 0.46$ in control subjects and $28.37 \pm 0.47$ in the patients with $\beta^{0}$-thalassemia/ $\mathrm{HbE}(\mathrm{P}=0.5037)$ (data not shown).

The expression levels of miR-451 and miR-155, which are expressed in mature and early erythroid cells (19), respectively, were compared between the plasma samples of the 16 control subjects and 23 patients with $\beta^{0}$-thalassemia/HbE. The average $\mathrm{C}_{\mathrm{q}}$ values of miR-451 and miR-155 were $30.5 \pm 0.37$ and $36.57 \pm 0.33$, in control subjects, respectively, and $27.375 \pm 0.67$ and $34.475 \pm 0.58$ in patients with $\beta^{0}$-thalassemia/HbE, respectively (data not shown). As indicated by the $\Delta \mathrm{C}_{\mathrm{q}}$ values, the levels of plasma miR-451 and miR-155 following normalization to 1 fmol synthetic cel-miR-39 were upregulated in the $\beta^{0}$-thalassemia/HbE plasma samples when compared with the control samples (miR-451, $\mathrm{P}=0.0001$; miR-155, $\mathrm{P}=0.0038$; Fig. 1A).

Correlation between plasma miR-451, miR-155 levels and disease severity. The correlation of miR-451 and miR-155 with disease severity, as well as additional clinical data was then analyzed. The severity grading was categorized using the criteria proposed by Sripichai et al (29). The level of miR-451 expression was significantly associated with disease severity (Fig. 1B). The level of miR-451 was significantly higher in severe cases than that observed in mild cases $(P=0.0101$; Fig. 1B). In addition, the miR-451 levels in mild cases were 
Table I. Hematological and clinical parameters of patients with $\beta^{0}$-thalassemia/HbE and normal control subjects.

\begin{tabular}{lccc}
\hline Clinical parameters & Control $(\mathrm{n}=16)$ & Mild $(\mathrm{n}=10)$ & Severe $(\mathrm{n}=13)$ \\
\hline Gender (male/female) & $5 / 11$ & $4 / 6$ & $7 / 6$ \\
RBC count $\left(1 \times 10^{9}\right.$ cells/ml) & $4.42 \pm 0.19^{\mathrm{a}}$ & $4.19 \pm 0.32^{\mathrm{b}}$ & $3.38 \pm 0.16$ \\
$\mathrm{Hb}(\mathrm{g} / \mathrm{dl})$ & $13.29 \pm 0.60^{\mathrm{a}}$ & $7.84 \pm 0.33^{\mathrm{b}}$ & $6.37 \pm 0.35$ \\
$\mathrm{Hct}(\%)$ & $39.0 \pm 1.61^{\mathrm{a}}$ & $24.77 \pm 0.98$ & $22.51 \pm 0.95$ \\
$\mathrm{MCV}(\mathrm{fl})$ & $85.29 \pm 1.48^{\mathrm{a}}$ & $60.45 \pm 2.26^{\mathrm{b}}$ & $67.22 \pm 2.06$ \\
$\mathrm{MCH}(\mathrm{pg})$ & $29.20 \pm 0.49^{\mathrm{a}}$ & $19.11 \pm 0.72$ & $20.02 \pm 0.68$ \\
MCHC $(\mathrm{g} / \mathrm{dl})$ & $34.65 \pm 0.10^{\mathrm{a}}$ & $31.59 \pm 0.17^{\mathrm{b}}$ & $29.76 \pm 0.42$ \\
Reticulocyte count $\left(1 \times 10^{9}\right.$ cells/l) & $49.76 \pm 4.23^{\mathrm{a}}$ & $137.70 \pm 19^{\mathrm{b}}$ & $456.70 \pm 53.73$ \\
Platelet count $\left(1 \times 10^{3}\right.$ cells/ml) & $288.72 \pm 26.73^{\mathrm{a}}$ & $220.90 \pm 20.08^{\mathrm{b}}$ & $684.92 \pm 75.92$ \\
Number of splenectomized patients & 0 & 0 & 10
\end{tabular}

${ }^{\mathrm{a}} \mathrm{P}<0.05$ vs. total $\beta^{0}$-thalassemia/HbE patients; ${ }^{\mathrm{b}} \mathrm{P}<0.05$ vs. severe cases of $\beta^{0}$-thalassemia/HbE. HbE, hemoglobin E; mild, patients with mild $\beta^{0}$-thalassemia/HbE; severe, patients with severe $\beta^{0}$-thalassemia/HbE; RBC, red blood cells; Hb, hemoglobin; Hct, hematocrit; MCV, mean corpuscular volume; $\mathrm{MCH}$, mean corpuscular hemoglobin; $\mathrm{MCHC}$, mean corpuscular hemoglobin concentration.
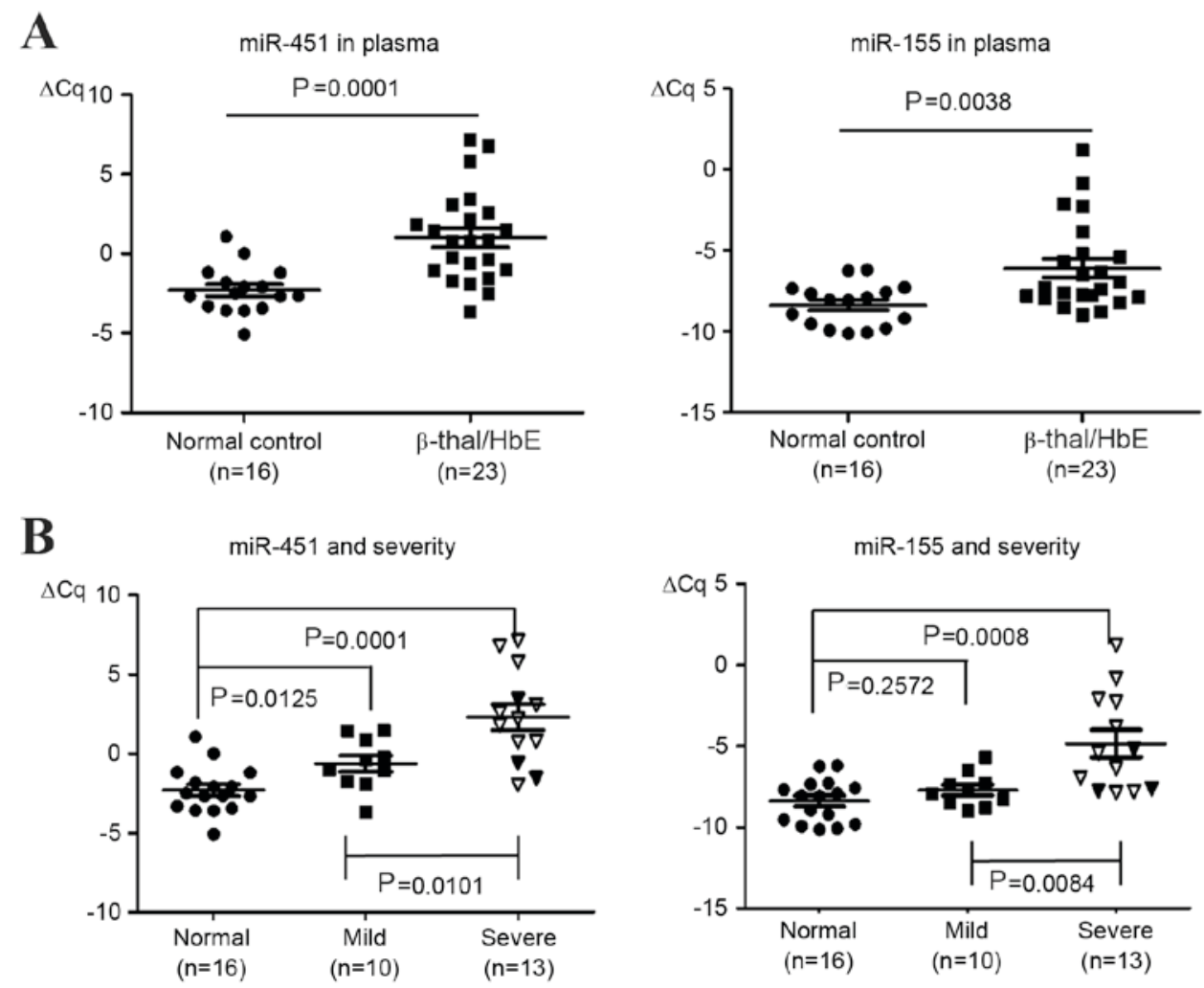

Figure 1. Increased levels of plasma miR-451 and miR-155 in patients with $\beta^{0}$-thalassemia/HbE. $\Delta \mathrm{C}_{\mathrm{q}}$ values of miRNA-451 and miRNA-155 were calculated using the $C_{q}$ values of the internal control, cel-miR-39. (A) Patients with $\beta^{0}$-thalassemia/HbE exhibited significantly higher plasma miR-451 and miR-155 levels when compared with normal control subjects. (B) The association between plasma miR-451, miR-155 levels, and disease severity was analyzed using the Student's $t$-test (black triangles, $\Delta \mathrm{C}_{\mathrm{q}}$ values of patients without splenectomy; white triangles, $\Delta \mathrm{C}_{\mathrm{q}}$ values of the patients that had undergone splenectomy). Plasma miR-451 and miR-155 levels were significantly associated with the degree of $\beta^{0}$-thalassemia/HbE disease severity. The severe cases exhibited significantly higher levels of miR-451 and miR-155 when compared with the control subjects and mild cases. HbE, hemoglobin E; $\mathrm{C}_{q}$, quantification cycle; miR, microRNA.

significantly higher when compared with the levels observed in normal control subjects $(\mathrm{P}=0.0125$; Fig. 1B). Similarly, the miR-155 levels in severe cases were significantly higher than those observed in the mild cases ( $\mathrm{P}=0.0084$; Fig. 1B). However, no significant difference in miR-155 levels was observed between mild cases and the normal controls
(Fig. 1B). In addition, significantly higher levels of plasma miR-451 were observed in patients that had been splenectomized $(n=10)$ when compared to those that were not $(n=13$; $\mathrm{P}=0.0005)$, with the miR-451 levels in the 3 severe patients that had not undergone a splenectomy falling within the range exhibited by the mild cases (Fig. 1). In order to evaluate the 
normal vs mild

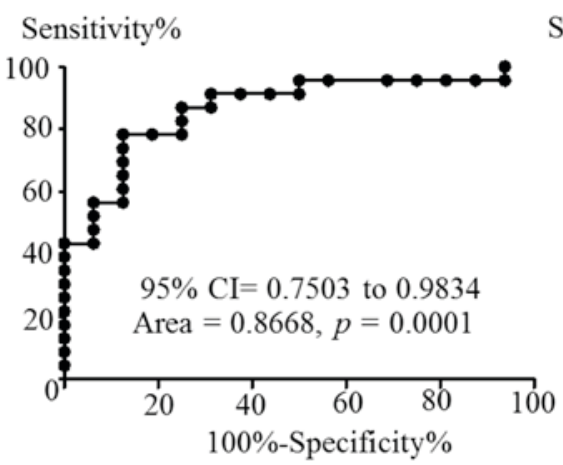

Sensitivity $\%$

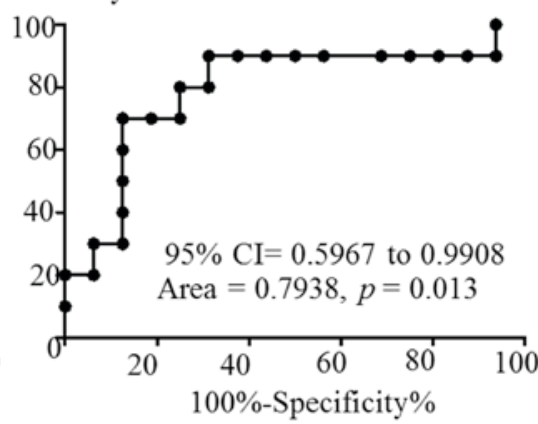

mild vs severe

Sensitivity\%

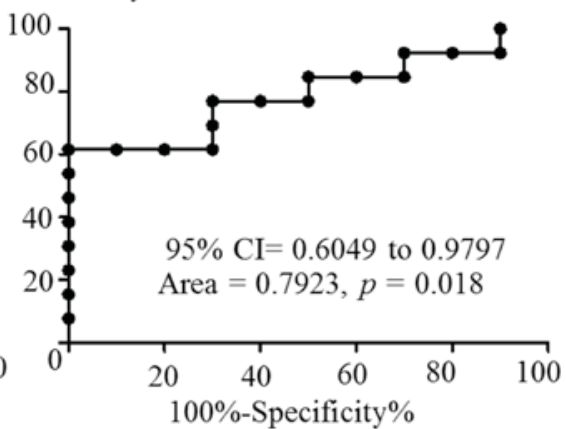

B

normal vs $\beta$ thal/HbE

normal vs mild

mild vs severe
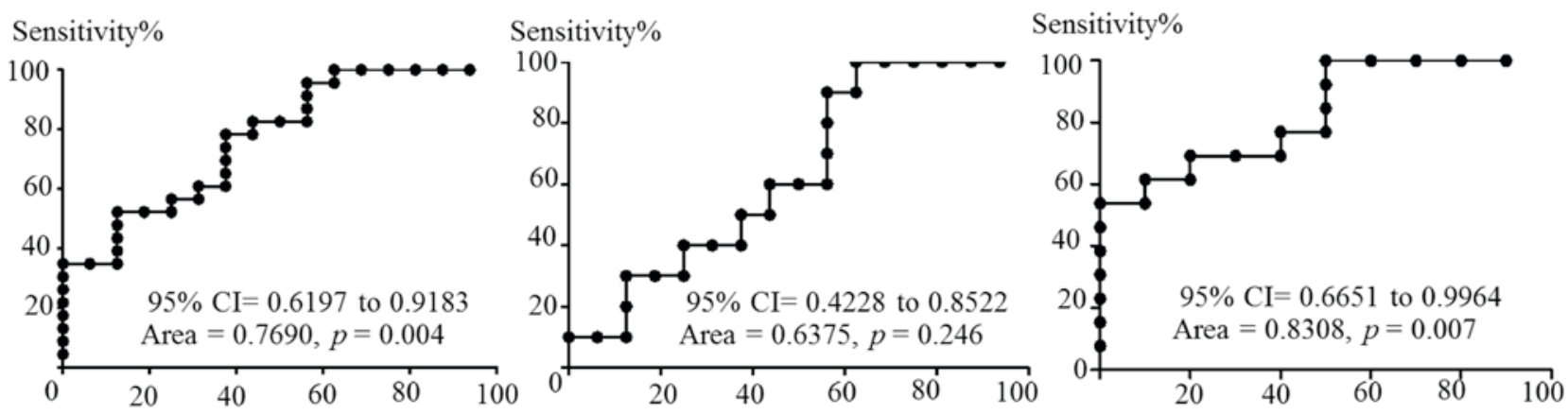

Figure 2. ROC analysis of plasma miR-451 and miR-155 levels. ROC analysis of plasma (A) miR-451 and (B) miR-155 levels in normal control subjects $(\mathrm{n}=16), \beta^{0}$-thalassemia/HbE patients $(\mathrm{n}=23)$ and those with mild $(\mathrm{n}=10)$ and severe disease $(\mathrm{n}=13)$. The sensitivity and specificity values were defined as the maximized AUC with 95\% CI value. ROC, receiver operating characteristic; miR, microRNA; HbE, hemoglobin E; AUC, area under the ROC curve; CI, confidence interval.

diagnostic value of plasma miR-451 and miR-155, the $\Delta \mathrm{C}_{\mathrm{q}}$ values of miR-451 and miR-155 from the two subject groups were used to construct ROC curves. The discriminating data between control and $\beta^{0}$-thalassemia/HbE groups was observed with an AUC of $0.8668(\mathrm{P}=0.0001)$ for miR-451 and 0.7690 ( $\mathrm{P}=0.004)$ for miR-155 (Fig. 2). As shown in Fig. 2A, plasma miR-451 may discriminate between normal controls and patients with mild disease (AUC $=0.7938 ; \mathrm{P}=0.013$ ), or between patients with mild and severe disease (AUC $=0.7923$; $\mathrm{P}=0.018$ ). However, the AUC for miR-155 demonstrated that this sequence may only discriminate between normal controls and patients with $\beta^{0}$-thalassemia/HbE or between mild and severe cases ( $\mathrm{AUC}=0.8308 ; \mathrm{P}=0.007)$, but not between normal and mild cases $(\mathrm{AUC}=0.6375 ; \mathrm{P}=0.246 ;$ Fig. $2 \mathrm{~B}$ ).

Correlation between plasma miR-451 and miR-155 levels and clinical features. The association between plasma miR-451 or miR-155 and clinical features, including RBC count, Hb, Hct, $\mathrm{MCV}, \mathrm{MCH}$ and $\mathrm{MCHC}$ was investigated. Notably, elevated plasma levels of miR-451 and miR-155 were significantly correlated with reticulocyte and platelet counts (Fig. 3). No statistically significant association between the levels of miR-451 and miR-155 and any additional clinical parameters, including $\mathrm{RBC}$ count, $\mathrm{Hb}$, Hct, $\mathrm{MCV}, \mathrm{MCH}$ or $\mathrm{MCHC}$, was observed (data not shown).
Level of miR-451 in packed red cells. In order to investigate whether the level of cellular miR-451 expression was deregulated in $\mathrm{RBCs}$ from patients with $\beta^{0}$-thalassemia/HbE, miR-451 levels in mature RBCs collected from the same subject cohort were analyzed. The levels of cellular miR-451 were not significantly different in control subjects when compared with patients with $\beta$-thalassemia/HbE, or in patients with mild compared with severe cases of the disease (Fig. 4).

\section{Discussion}

Patients with $\beta^{0}$-thalassemia/HbE exhibit major $\mathrm{RBC}$ abnormalities as a result of precipitation of excess $\alpha$ globin chains which are unable to form a stable tetramer. Therefore, a globin chains precipitate as inclusion bodies leading to the ineffective erythropoiesis and immature destruction of $\mathrm{RBCs}(5) . \beta^{0}$-thalassemia/HbE is traditionally classified as a disease with extravascular hemolysis in addition to ineffective erythropoiesis (5). However, previous studies have provided evidence of intravascular hemolysis as indicated by increased serum-free $\mathrm{Hb}$ levels and depleted levels of plasma haptoglobin protein $(30,31)$. Several conventional techniques have been developed for the assessment of hemolysis, including the detection of lactate dehydrogenase ( $\mathrm{LDH})$, serum haptoglobin 
A

$\operatorname{miR}-451$

Reticulocyte $(10 \%)$

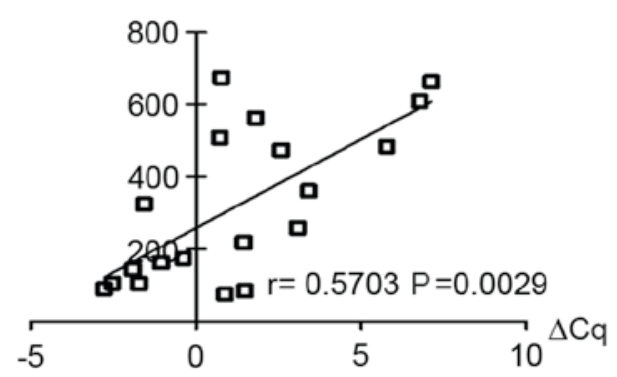

B

$\operatorname{miR}-451$

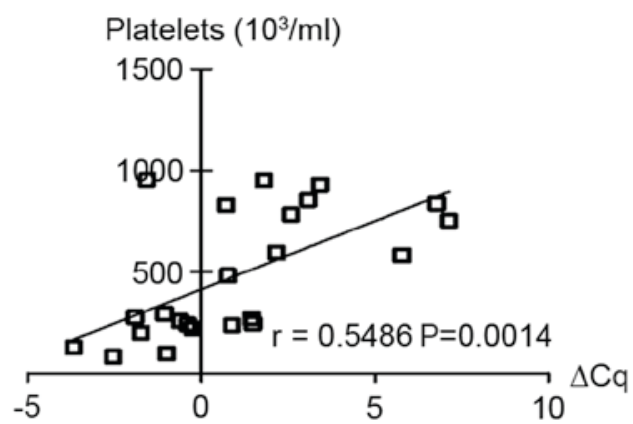

miR-155

Reticulocyte $\left(10^{9} / 1\right)$

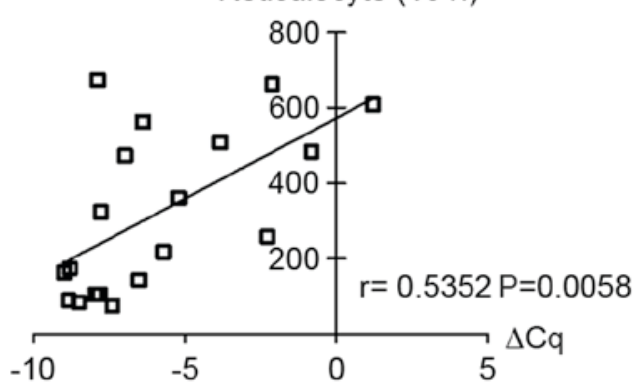

miR-155

Platelets $\left(10^{3} / \mathrm{ml}\right)$

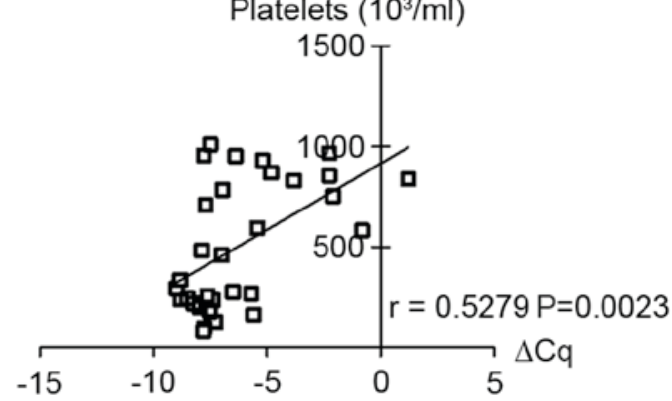

Figure 3. Correlation between the level of miR-451 and miR-155 and clinical features. Levels of miR-451 and miR-155 correlated with (A) reticulocyte and (B) platelet counts as depicted by plots of miR-451 and miR-155 $\Delta \mathrm{C}_{\mathrm{q}}$ values against the absolute number of reticulocytes and platelets. Data were analyzed using a Pearson's correlation test. miRNA, microRNA; $\mathrm{C}_{\mathrm{q}}$, quantification cycle.
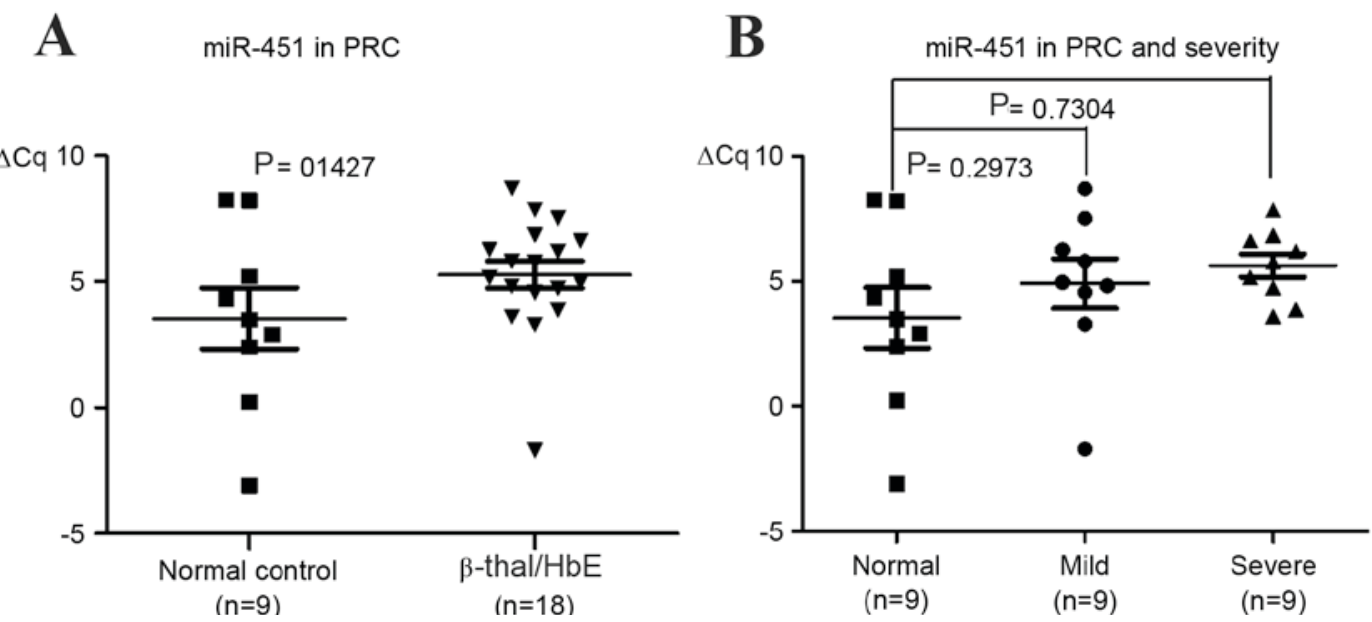

Figure 4. miR-451 levels in PRCs. (A) The levels of miR-451 in PRCs from 9 control subjects and 18 patients with $\beta^{0}$-thalassemia/HbE. (B) The levels of miR-451 between normal control, and patients with mild and severe cases of $\beta^{0}$-thalassemia/HbE. $\Delta \mathrm{C}_{\mathrm{q}}$ values of miRNA-451 in PRCs were calculated using the following formula: $\Delta \mathrm{C}_{\mathrm{q}}=\mathrm{C}_{\mathrm{q( \text {miR-45) }}} \mathrm{C}_{\mathrm{q}(\mathrm{miR} \text {-let7a) }}$. miR, microRNA; PRC, packed red cells; HbE, hemoglobin $\mathrm{E}$; $\mathrm{C}_{\mathrm{q}}$, quantification cycle.

and serum-free $\mathrm{Hb}$ levels, as well as urine-free $\mathrm{Hb}$, urine hemosiderin, and erythrocyte survival and indirect bilirubin tests $(32,33)$. A number of conventional techniques may not be suitable for routine clinical use, such as the detection of erythrocyte survival with a radionuclide chromium 51 labeling method, which requires exclusive equipment for radioactive materials and a prolonged examination period with a series of blood samples (34). LDH is considered to be a useful clinical marker of intravascular hemolysis; however, it is not specific as LDH is released from neoplastic cells, the liver, or from damaged organs (35). The present study aimed to develop a novel and specific method for assessing the degree of hemolysis in $\beta^{0}$-thalassemia/HbE patients. Previous studies have demonstrated that miRNAs are present in the circulation with high stability, and the profile of circulating miRNAs reflects the pathophysiological processes of a number of human diseases (18).

A number of miRNAs serve important roles in the regulation of erythropoiesis $(16,19)$. A previous study revealed that miR-451 expression may be associated with the production of 
erythroid cells in a lineage- and stage-specific manner (20). Analysis of the expression patterns of miR-451 during normal erythropoiesis revealed that the expression of miR-451 was upregulated during late erythropoiesis (19). A previous study demonstrated that circulating RBCs contain high levels of miR-451 expression, with $\sim 10,000$-fold greater levels than granulocytes (19). Expression of miR-451 is dependent on the Argonaute 2 protein and is restricted to the erythroid lineage. Mice deficient in the miR-451 cluster exhibited impaired erythroid maturation, ineffective erythropoiesis and mild anemia (36). The present study evaluated the possibility that intracellular hemolysis may result in increased levels of plasma miR-451. The levels of plasma miR-451 in patients with $\beta^{0}$-thalassemia/HbE were elevated and miRNA levels correlated with disease severity. To the best of our knowledge, the present study demonstrated the suitability of using plasma miR-451 as a biomarker for erythroid cell destruction in $\beta^{0}$-thalassemia/HbE patients for the first time. Consistent with the results of a previous study (24), no alteration in the levels of cellular miR-451 in erythrocytes between control subjects and $\beta^{0}$-thalassemia/HbE patients was observed. This indicated that the increased levels of plasma miR-451 may be as a result of erythroid cell destruction and not from the increased miR-451 levels in RBCs. The level of miR-451 was strongly associated with disease severity, and the authors hypothesize that variations in plasma miR-451 levels may result from differences in the degree of intravascular hemolysis in each patient. Notably, the patients that had undergone a splenectomy exhibited higher levels of plasma miR-451 than those that had not. Splenectomy is used to manage severe cases of $\beta^{0}$-thalassemia to reduce spleen-induced extravascular hemolysis. In addition, intravascular hemolysis has been reported in splenectomy patients (10). The results of the present study suggest that elevated levels of circulating miRNA-451 may be a result of red cell destruction via the intravascular hemolysis pathway in splenectomy patients.

In the present study, the level of plasma miRNA-155, which is expressed in early erythroid cells, was measured. miR-155 has been previously characterized as a multifunctional miRNA that serves important roles in the pathological processes of a number of diseases, particularly cancer, inflammation, immunity and cardiovascular diseases (25). In addition, the overexpression of miR-155 as an oncogenic miRNA in hematological malignancies and solid tumors has been reported $(26,27)$. The levels of plasma miR-155 in patients with $\beta^{0}$-thalassemia/HbE were significantly higher when compared with control subjects. However, no correlation between miR-155 expression and disease severity was observed, as the levels of miR-155 in control subjects and mild cases were not significantly different. The level of plasma miR-155 is very low, and is detected at $>35 \mathrm{C}_{\mathrm{q}}$. Therefore, plasma miR-155 expression may be undetected, which may lead to false-negative results in some cases.

In conclusion, the present study demonstrated that reticulocyte counts in the circulation were increased in patients with $\beta^{0}$-thalassemia/HbE when compared to normal controls. In addition, reticulocyte counts were associated with the level of circulating miR-451. Reticulocytes are immature erythrocytes, which are released from the bone marrow into the blood circulation. Increased reticulocyte numbers reflect a response to anemia induced by hemolysis or the loss of erythrocytes, by accelerated erythropoiesis in the bone marrow. The results of the present study indicate that the increased levels of circulating miRNA-451 observed during $\beta^{0}$-thalassemia/HbE may result from the accelerated erythropoiesis-associated destruction of erythroid cells. In conclusion, the observations suggest that the measurement of plasma miR-451 may be a relevant biomarker of intravascular hemolysis in patients with $\beta^{0}$-thalassemia/HbE.

\section{Acknowledgements}

The present study was supported, in part, by the Thailand Research Fund (grant no. RMU5380001), the Research Chair Grant, National Science and Technology Development Agency (NSTDA), the Exchange Program for East Asian Young Hematologists, sponsored by the Japan Society for the Promotion of Science and the Chulalongkorn University Ratchadaphisek Somphot Endowment Fund. The manuscript was corrected by Dr Valery Combes (Faculty of Sciences, School of Life Sciences, University of Technology, Sydney, NSW, Australia).

\section{References}

1. Olivieri NF: The beta-thalassemias. N Engl J Med 341: 99-109, 1999.

2. Fucharoen S and Winichagoon P: Clinical and hematologic aspects of hemoglobin E beta-thalassemia. Curr Opin Hematol 7: $106-112,2000$

3. Vichinsky E: Hemoglobin e syndromes. Hematology Am Soc Hematol Educ Program 79-83, 2007.

4. Fucharoen S and Winichagoon P: Hemoglobinopathies in southeast Asia. Hemoglobin 11: 65-88, 1987.

5. Rund D and Rachmilewitz E: Beta-thalassemia. N Engl J Med 353: 1135-1146, 2005.

6. Olivieri NF, Pakbaz Z and Vichinsky E: Hb E/beta-thalassaemia: A common \& clinically diverse disorder. Indian J Med Res 134: 522-531, 2011.

7. Thein SL: Pathophysiology of beta thalassemia-a guide to molecular therapies. Hematology Am Soc Hematol Educ Program 31-37, 2005

8. Weatherall DJ CJ: The thalassemia syndromes. Malden MA Blackwell Science, 2001.

9. Conran N: Intravascular hemolysis: A disease mechanism not to be ignored. Acta Haematol 132: 97-99, 2014.

10. Atichartakarn V,ChuncharuneeS,ArchararitN,UdomsubpayakulU and Aryurachai K: Intravascular hemolysis, vascular endothelial cell activation and thrombophilia in splenectomized patients with hemoglobin E/ $\beta$-thalassemia disease. Acta Haematol 132: 100-107, 2014.

11. Bartel DP: MicroRNAs: Genomics, biogenesis, mechanism, and function. Cell 116: 281-297, 2004.

12. Filipowicz W, Bhattacharyya SN and Sonenberg N: Mechanisms of post-transcriptional regulation by microRNAs: Are the answers in sight? Nat Rev Genet 9: 102-114, 2008.

13. Miska EA: How microRNAs control cell division, differentiation and death. Curr Opin Genet Dev 15: 563-568, 2005.

14. Roth C,Rack B,Müller V,Janni W,Pantel K and Schwarzenbach H: Circulating microRNAs as blood-based markers for patients with primary and metastatic breast cancer. Breast Cancer Res 12: R90, 2010.

15. Lawrie CH, Gal S, Dunlop HM, Pushkaran B, Liggins AP, Pulford K, Banham AH, Pezzella F, Boultwood J, Wainscoat JS, et al: Detection of elevated levels of tumour-associated microRNAs in serum of patients with diffuse large B-cell lymphoma. Br J Haematol 141: 672-675, 2008.

16. Chen Y, Gelfond JA, McManus LM and Shireman PK: Reproducibility of quantitative RT-PCR array in miRNA expression profiling and comparison with microarray analysis. BMC Genomics 10: 407, 2009. 
17. Reid G, Kirschner MB and van Zandwijk N: Circulating microRNAs: Association with disease and potential use as biomarkers. Crit Rev Oncol Hematol 80: 193-208, 2011.

18. Mitchell PS, Parkin RK, Kroh EM, Fritz BR, Wyman SK, Pogosova-Agadjanyan EL, Peterson A, Noteboom J, O'Briant KC Allen A, et al: Circulating microRNAs as stable blood-based markers for cancer detection. Proc Natl Acad Sci USA 105: 10513-10518, 2008.

19. Masaki S, Ohtsuka R, Abe Y, Muta K and Umemura T: Expression patterns of microRNAs 155 and 451 during normal human erythropoiesis. Biochem Biophys Res Commun 364: 509-514, 2007.

20. Pase L, Layton JE, Kloosterman WP, Carradice D, Waterhouse PM and Lieschke GJ: miR-451 regulates zebrafish erythroid maturation in vivo via its target gata2. Blood 113: 1794-1804, 2009.

21. Kim M, Tan YS, Cheng WC, Kingsbury TJ, Heimfeld S and Civin CI: MIR144 and MIR451 regulate human erythropoiesis via RAB14. Br J Haematol 168: 583-597, 2015.

22. Bruchova-Votavova H, Yoon D and Prchal JT: miR-451 enhances erythroid differentiation in K562 cells. Leuk Lymphoma 51: 686-693, 2010.

23. Zhan M, Miller CP, Papayannopoulou T, Stamatoyannopoulos G and Song CZ: MicroRNA expression dynamics during murine and human erythroid differentiation. Exp Hematol 35: 1015-1025, 2007.

24. Svasti S, Masaki S, Penglong T, Abe Y, Winichagoon P, Fucharoen S and Umemura T: Expression of microRNA-451 in normal and thalassemic erythropoiesis. Ann Hematol 89: 953-958, 2010.

25. Faraoni I, Antonetti FR, Cardone J and Bonmassar E: miR-155 gene: A typical multifunctional microRNA. Biochim Biophys Acta 1792: 497-505, 2009.

26. Zhu W, Qin W, Atasoy U and Sauter ER: Circulating microRNAs in breast cancer and healthy subjects. BMC Res Notes 2: 89, 2009.

27. Eis PS, Tam W, Sun L, Chadburn A, Li Z, Gomez MF, Lund E and Dahlberg JE: Accumulation of miR-155 and BIC RNA in human B cell lymphomas. Proc Natl Acad Sci USA 102: 3627-3632, 2005.
28. Winichagoon P, Saechan V, Sripanich R, Nopparatana C, Kanokpongsakdi S, Maggio A and Fucharoen S: Prenatal diagnosis of beta-thalassaemia by reverse dot-blot hybridization. Prenat Diagn 19: 428-435, 1999.

29. Sripichai O, Makarasara W, Munkongdee T, Kumkhaek C, Nuchprayoon I, Chuansumrit A, Chuncharunee S, Chantrakoon N, Boonmongkol P, Winichagoon P and Fucharoen S: A scoring system for the classification of beta-thalassemia/HbE disease severity. Am J Hematol 83: 482-484, 2008.

30. Arce-Bejarano R, Lomonte B and Gutiérrez JM: Intravascular hemolysis induced by the venom of the Eastern coral snake, Micrurus fulvius, in a mouse model: Identification of directly hemolytic phospholipases A2. Toxicon 90: 26-35, 2014.

31. Ragab SM, Safan MA and Badr EA: Study of serum haptoglobin level and its relation to erythropoietic activity in Beta thalassemia children. Mediterr J Hematol Infect Dis 7: e2015019, 2015.

32. Okumiya T, Ishikawa-Nishi M, Doi T, Kamioka M, Takeuchi H, Doi Y and Sugiura T: Evaluation of intravascular hemolysis with erythrocyte creatine in patients with cardiac valve prostheses. Chest 125: 2115-2120, 2004.

33. Rother RP, Bell L, Hillmen P and Gladwin MT: The clinical sequelae of intravascular hemolysis and extracellular plasma hemoglobin: A novel mechanism of human disease. JAMA 293: 1653-1662, 2005.

34. Mock DM, Matthews NI, Zhu S, Strauss RG, Schmidt RL, Nalbant D, Cress GA and Widness JA: Red blood cell (RBC) survival determined in humans using RBCs labeled at multiple biotin densities. Transfusion 51: 1047-1057, 2011.

35. Painter PC, Van Meter S, Dabbs RL and Clement GE: Analytical evaluation and comparison of Dupont aca lactate dehydrogenase-1 (LD1) isoenzyme assay diagnostic efficiency for acute myocardial infarction detection with other LD1 methods and aca CK-MB. A two-site study. Angiology 45: 585-595, 1994.

36. Rasmussen KD, Simmini S, Abreu-Goodger C, Bartonicek N, Di Giacomo M, Bilbao-Cortes D, Horos R, Von Lindern M, Enright AJ and O'Carroll D: The miR-144/451 locus is required for erythroid homeostasis. J Exp Med 207: 1351-1358, 2010. 